\title{
Irresolvable Disagreement, Objectivist Antirealism and Logical Revision
}

\author{
Manfred Harth ${ }^{1}$
}

Received: 12 February 2019 / Accepted: 27 March 2020 / Published online: 10 April 2020

(c) The Author(s) 2020

\begin{abstract}
Meta-ethical realism faces the serious epistemological problem of how to explain our epistemic access to moral reality. In the face of this challenge many are sceptical about non-naturalist realism. Nonetheless, there is good reason to acknowledge moral objectivity: morality shows all the signs of a truth-apt discourse but doesn't exhibit the typical relativity inducing features. This suggests a middle-ground position, a theory that embraces the virtues of realism but does avoid its vices: objectivist antirealism. In this paper, I'll discuss, mainly following Crispin Wright's account of moral truth as superassertibility, a promising version of objectivist antirealism and show how to cope with notorious problems, notably those arising from the thought that moral disagreement might be possible in which nobody is guilty of a cognitive shortcoming, which contradicts the antirealist claim that moral truth is not beyond our epistemic reach. The solution is to deny the possibility of cognitively faultless moral disagreement by arguing that cognitively blameless thinkers either agree or stay agnostic and, therefore, never disagree about any moral proposition. Since assuming an agnostic stance on the part of such thinkers contradicts the antirealist's conception of truth-even within the limits of intuitionistic logic-I'll propose an alternative logical revision for the moral discourse: a three-valued logic with epistemically construed truth-values.
\end{abstract}

\section{Introduction: Realism, the Problem of Epistemic Access and Moral Objectivity}

How do we attain moral knowledge? Genuine moral facts or properties, if there are any, are supposed to be causally inert. So knowledge about them seems impossible. This, of course, is true only if knowledge presupposes causal contact with the relevant facts or properties, at least indirectly. The thesis that genuine moral facts are part of the furniture of the universe is in epistemological troubles: the proponent of

Manfred Harth

manfred.harth@1rz.uni-muenchen.de

1 Ludwig-Maximilians-Universität München, Ludwigstr. 31, 80539 Munich, Germany 
such a view, i.e. the non-naturalist or robust realist, does not seem to be in a position to explain how knowledge about moral facts is possible. ${ }^{1}$ A particularly important epistemological challenge to robust realism, therefore, is to account for our epistemic access to and our knowledge about moral reality. As already noted, the challenge thus stated presupposes a theory of knowledge that poses a causal condition on knowledge — and such theory is not uncontroversial (see e.g. Clarke-Doane 2012; Enoch 2011: 154, esp. footnote 8). But how not put this epistemological challenge in terms of knowledge, causal contact, epistemic access or some such? Recently David Enoch (2011: 158-165) stated an alternative and more general version of the challenge at dispute, which is couched in terms of a correlation between our moral beliefs and the moral facts: the robust realist has to show that there is a more than accidental link between our (justified) true moral beliefs and the moral facts, i.e. a probability (significantly) higher than random probability for our moral beliefs to be true, so that they are not just flukes. If robust realists are not in a position to explain that correlation, any epistemic justification they may have had for their moral beliefs is defeated or undermined. Enoch (2011, ch. 7) presents an evolutionary solution to this correlation challenge. It is a third-factor explanation of the correlation between our moral beliefs and the moral facts in which evolution plays the role of the third "pre-establishing" factor: the selective forces of evolution have shaped our moral beliefs and the same forces also brought forth the survival of the human species, and, since evolution's "achievement", viz. the survival of our species, is good, evolution is closely (enough) related to the (other) moral facts. However, this sort of explanation raises serious questions of various kinds (cf. Behrends 2013; Braddock 2016; Enoch 2011; ch. 7, Sepielli 2012). Is the (kind of) goodness of evolution's “achievement", i.e. the survival of the Homo sapiens, really relevant to morality? Is the relation between evolution's "achievement" and its (allegedly moral) goodness not by itself an inexplicable random coincidence, a "miracle"? Is it really the case that the patterns of behaviour conducive to the survival of our species are morally good, rather than "neutral" or even (in part) morally wrong? Is the correlation between the (alleged) fact that our evolutionary survival is good and the huge amount of the (other) moral facts not too weak to bear the explanatory burden of the evolutionary explanation of the correlation between our moral beliefs and the moral facts? And does this evolutionary explanation not involve a vicious circle, since the explanation itself relies on moral beliefs in order to explain the reliability of our moral beliefs? The bottom line is that the evolutionary solution is highly speculative in various respects and, on the whole, shows too many imponderables. Even die-hard realists, as Enoch (ibid.), concede that, from an epistemological point of view, robust realism loses plausibility (points) as opposed to antirealist (and also naturalist) positions, which have the resources to easily explain the relevant correlation and to solve the

\footnotetext{
1 Meta-ethical non-natural or robust realism is the following thesis (cf. Enoch 2011: 3f): moral beliefs have truth-apt contents some of which are true in virtue of moral facts, which exist independently of us in relevant ways, notably independent of our (actual or idealized) attitudes and beliefs about them, and the moral contents and facts are not reducible to contents or facts of other kinds, notably not reducible to natural (physical, biological, psychological, sociological) contents or facts.
} 
problem of moral knowledge and epistemic access (since there is no genuine moral realm to be accessed in the first place). Yet antirealist theories-notably the wellestablished varieties: non-cognitivism, relativism, fictionalism, error theory-face serious troubles as well and so, too, lose plausibility (points) in other areas. Most of the antirealist's problems are due to her denial of moral objectivity ${ }^{2}$ : morality shows all the signs of a truth-apt discourse but doesn't exhibit the typical relativity inducing features, like e.g. discourse about matters of taste does. So, the claim that moral sentences aren't truth-apt, the claim that there are no moral truths and the claim that moral truth is relative (to a perspective or some such) are highly contestable and in need of thorough but so far yet outstanding underpinning. Hence, it is fair to say, a meta-ethical theory would be at an advantage that avoids both the epistemological problems of realism and the problems of the various shapes of antirealism, at least those problems due to their denial of moral objectivity. Such middle-ground theory would combine a rejection of realism with acknowledging moral objectivity: objectivist antirealism. The challenge, of course, is to coherently state such a position in the first place. In this paper, I'll outline this objectivist antirealism, which is based on Crispin Wright's antirealist or epistemic conception of moral truth, and I'll argue that it can be stated coherently and defend it against notorious objections, notably one that arises from the assumption that rationally irresolvable, or cognitively faultless, moral disagreement is possible.

Since the course of argument in this paper is quite intricate and leads the reader into some side branches and dead ends, it might be helpful to outline the argument in more detail than is perhaps usual on these occasions.

In the next section, I delineate my favoured objectivist antirealism, clarify key concepts and discuss and refute certain objections to this position, which represents a middle-ground view between the extremes of non-cognitivism/relativism and realism. In Sect. 3, I present the argument from faultless disagreement and the related EC-deduction introduced by Crispin Wright. This argument is supposed to refute the pre-theoretically plausible assumption that cognitively faultless moral disagreement is possible. Following a thought of Folke Tersman's, I now show how the realist is able to escape the argument and can thus acknowledge the possibility of faultless disagreement: she can draw on an equivocation regarding knowability (of a moral truth). Within the framework of objectivist antirealism, however, this manoeuvre does not succeed, as I will show: In this framework, the possibility of faultless disagreement due to the epistemic conception of truth leads to contradiction. The advocate of objectivist antirealism must therefore deny this possibility and explain why this pre-theoretical intuition is misleading. In Sect. 4, I propose a solution: Instead of acknowledging that because of the now admitted impossibility of faultless disagreement any moral disagreement is solvable and in principle a moral agreement can be found (by cognitively faultless thinkers), the proponent of objectivist antirealism

\footnotetext{
${ }^{2}$ Moral objectivity is understood here as comprising the following features: (a) moral sentences are truth-apt, (b) some of them are true, (c) they express genuine or irreducibly moral propositions, (d) propositional truth is not relative, i.e. moral assertions or beliefs are correct, or their contents are true, simpliciter.
} 
should claim that cognitively faultless thinkers would adopt an agnostic stance with respect to those moral propositions they cannot agree on. This would explain why we have the intuition that cognitively faultless disagreement is possible, but at the same time one can deny this possibility, since faultless thinkers would have no disagreement at all as regards the relevant propositions (since they would be agnostic). But even this suggestive solution is not available in objectivist antirealism because of its epistemic conception of truth: the assumption of agnostic faultless thinkers with respect to a certain proposition implies a contradiction. Preliminary conclusion: the adherent of objectivist antirealism must deny the possibility of faultless moral disagreement and at the same time acknowledge that any moral disagreement can in principle be solved by the parties reaching a moral agreement. But the latter in particular is highly implausible: it seems to arise more from optimism and wishful thinking than from any convincing argument. That is why I reject this solution. Objectivist antirealism therefore seems to have failed. In Sect. 5, I discuss an attempt to ward off this failure, which attempts to prevent the contradictions mentioned above by means of logical revision: the weakening of classical logic, which was hitherto assumed for moral discourse, to intuitionistic logic. But I also show why this solution does not work. Therefore, in the last Sect. 6, I propose a more radical logical solution, which seems to be the only remaining one for objectivist antirealism: the abandonment of classical logic in favour of a trivalent logic with epistemically construed truth values that congenially correspond to the truth conception of objectivist antirealism. This proposal can only be understood programmatically in the context of this paper: it is intended to encourage future (logical) research in this direction and to establish the middle-ground position of objectivist antirealism more strongly in the meta-ethical discourse.

\section{Objectivist Antirealism: Moral Truth as Stable Warrantability}

Traditionally objectivist antirealism has been put forward as a coherence theory of truth or as Peircean pragmatism or similar accounts. These antirealist theories are objectivist in that they, when applied to moral discourse, countenance genuine, irreducible moral propositions, some of which are supposed to be true, and conceive of their truth as a (allegedly) non-relative property, e.g. as maximum coherence, as rational acceptability under ideal epistemic conditions or as justifiability at the ideal limit of (scientific) investigation. However, those theories have been the target of much criticism, notably due to the (kind of) idealization they involve and their global claim. The antirealist theory to be considered here, however, is a more recent development that tries to avoid both the problematic type of idealization and the global approach: Crispin Wright's epistemic conception of truth (Wright 1992, 1996, 2002, 2006). It is a substantial account of truth that identifies moral truth, i.e. the property or nature of truth in the moral domain, with an epistemic property, viz. stable warrantability, that Wright has termed superassertibility. This is intended as a local claim, i.e. a claim about truth in the moral domain alone, so that this antirealism for the moral discourse would not entail antirealism in some other region of discourse. Thus, in order to avoid global antirealism, the antirealist has to 
presuppose alethic pluralism (cf. Edwards 2011, 2012a, b; Pedersen 2010, 2012a, b; Lynch 2009). This, in short, is the view that there is just one concept of truthwhich is a minimal or metaphysically neutral concept governed by so-called platitudes or truisms - but different properties of being true, or manifestations of it in virtue of which propositions are true, depending on the selected region of discourse. In detail, alethic pluralism comprises the following two claims (following Wright 1992: 24-36):

Minimalism The concept of truth is a minimal concept. That is to say, it is solely determined by a set of very general and intuitive principles, so-called platitudes, which are metaphysically neutral and connect truth to other concepts, e.g. the platitude that to assert is to present as true, that a belief is true just in case things are as they are believed to be and so on. The platitudes build up an analytic theory, or a network analysis, of the concept of truth. Consequently, any correct substantial account of truth that proposes to define the nature of truth, or the property of being true, has to satisfy the platitudes. If so it is a model of the analytic theory.

Pluralism The nature, or property, of truth may be different depending on the selected region of discourse. That is, over and above the minimal features of truth expressed by the platitudes there are extra features determining the domain-specific or local nature of truth in some targeted region of discourse, which may vary from region to region. There is no nature of truth across all areas, but possibly different properties depending on the selected region; and any such property is a model of the analytic theory provided it satisfies the platitudes. ${ }^{3}$

Hence, within a pluralist framework, moral truth may have an evidentially constraint and mind-dependent nature, whereas e.g. the truth of statements about the physical world is, or is manifested by, an evidentially unconstrained and mind-independent property. In particular, moral truth may be a somehow idealized epistemic property that is constructed out of ordinary epistemic properties such as warrantability or coherence.

There are two prominent accounts of moral truth of this shape, which are closely related: Crispin Wright's conception of truth as superassertibility (Wright 1992, 2003, 2006) and Michael Lynch's conception of truth as concordance, a specific shape of supercoherence (Lynch 2009). ${ }^{4}$ Superassertibility is assertibility not in some ideal, limiting state of information, but stable assertibility, i.e. the property of being warrantable in some actually accessible state of information and remaining so no matter what enlargements or improvements are made to it. Supercoherence is not maximum coherence, but the property of being coherent with some framework, e.g.

\footnotetext{
3 The pluralist accounts of Wright and Lynch differ in a certain respect that, however, is irrelevant for our discussion: on Wright's view, there is one concept of truth but there are possibly different properties of being true such that "true" or "truth" may designate different properties when used in different regions of discourse, whereas, according to Lynch, there is just one generic property of being true, which is a functional property, but there are possibly multiple manifestations of it, i.e. different domain-specific properties of propositions in virtue of which they are true. This difference is recently discussed as the distinction between strong and modest forms of pluralism (cf. Pedersen 2012b; Pedersen and Wright 2013).

4 But see also Dorsey's coherence theory of truth in the moral discourse (Dorsey 2006).
} 
some moral framework, and remaining so no matter what improvements are made to the initial framework. Concordance of a moral judgement is the property of being supercoherent with some moral framework combined with the truth of the morally relevant non-moral judgements of that framework (Lynch 2009: 176). In what follows, I'll confine myself to superassertibility, but nothing relevant for the discussion hinges on my choice instead of concordance (actually it will turn out that concordance is a special case of superassertibility). Wright introduces a range of concepts of superassertibility, rather than one single concept (cf. Wright 1992: 68), depending on the (perhaps domain-specific) interpretation of some key concepts or the range of the states-of-information quantifier employed in the definition of superassertibility; and he presents the definition in slightly different versions (Wright 1992: 48, 2003: 199, 2006: 56). For my purposes I distil the following working definition of superassertibility:

(S) P is superassertible iff there is some accessible state of information S such that $\mathrm{P}$ is warrantable in $\mathrm{S}$ and remains so no matter what enlargements or other forms of improvement are made to $\mathrm{S}$

An accessible state of information, in the moral realm, consists of a sufficiently coherent set of moral beliefs as well as morally relevant non-moral, especially empirical, beliefs which a person could acquire in the actual world (with its actual biological, neurological, psychological laws) under sufficiently favorable epistemic conditions (cf. Edwards 1996: 105-108; Wright 1992: 67-68).

Notoriously, two main problems arise for this (type of) definition of superassertibility (see e.g. Edwards 1996: 105-108; Wright 1992: 67-68): the first regards the question as to what is an accessible state of information, in particular as regards morality, and the second concerns the concept of enlargement or improvement (of a state of information) and the range of the corresponding states-of-information quantifier. The first problem has a straightforward solution for the moral domain. An accessible state of information, as mentioned in the definition of moral superassertibility, can be conceived of as consisting of two components that are interwoven: first, a sufficiently coherent set of moral beliefs achievable by some thinker $\mathrm{T}$ at time $\mathrm{t}$ on the basis of her actual beliefs and, second, a set of morally relevant non-moral, notably empirical information available to $\mathrm{T}$ at $\mathrm{t}$, i.e. a set of non-moral beliefs that would be, in the world as it actually is, generated in $\mathrm{T}$ at $\mathrm{t}$ by investigating in sufficiently favourable epistemic circumstances. The second problem, however, is more intricate. Nevertheless, I think that it can be given a quite satisfactory solution for the moral domain we are dealing with here. First, in definition (S), i.e. in the second half of the definiens, the quantification runs over all enlargements and other forms of improvement of some state of information. So, something has to be said about the range of this universal states-of-information quantifier. The following seems to be a plausible restriction: any enlarged or otherwise improved state of information, as any state of information mentioned or quantified over in the definition, is conceived of in such manner that it is accessible to somebody at some time in the world as it actually is. That is to say, enlargements and other forms of improvement are conceived of as, in principle, achievable in this world by human beings. This feature of 
improvement is decisive in the light of a certain objection against the identification of truth with superassertibility: the argument from defeated warrant originally presented by Skorupski (1988: 522). The argument says that for any state of information $\mathrm{S}$ it is conceivable that a statement $\mathrm{P}$ may be warranted in $\mathrm{S}$, lose its warrant in some improvement of $S$ and regain warrant in some further improvement. Since it seems to be quite plausible that $\mathrm{P}$ is true-the single intermediate gap of warrant in the chain of improvements should not threaten its truth status- $\mathrm{P}$ presumably is a true statement that isn't superassertible. This objection can be refuted as follows: $\mathrm{P}$ in fact is superassertible, because there is some state of information available to some thinker based on which $\mathrm{P}$ is stably warrantable, since, by my definition of improvement, any improvement of a state of information is a state that is accessible to somebody at some time. So whenever an intermediate gap of warrant appears in the chain of improvements of $\mathrm{S}$, any state of information subsequent to this gap is accessible to some thinker-and, therefore, $\mathrm{P}$ is superassertible. ${ }^{5}$

In addition to this actual achievability of any improved state of information, we can model the process of enlargement or improvement as an endless tree the root of which is the state of information available to somebody at some time and the knots are states of information such that any state on the tree is better than its predecessors. Since, in what follows, I'll consider enlargement to be a special case of improvement, I'll simply talk of improved or better states of information. So, the crucial question is: when is a state of information better than another state of information? It is natural to think of improving one's state of information in terms of increasing one's knowledge or approaching the truth. However, as regards the moral part of information at least, i.e. the relevant set of moral beliefs, we cannot conceive of improvement as a process that, inter alia, enhances the moral knowledge or approaches the moral truth, since then our characterization or grasp of the nature of moral truth in terms of superassertibility would be defective, viz. viciously circular: in order to grasp the nature of moral truth in terms of superassertibility we already need to have a grasp of what constitutes the truth of a moral belief, i.e. a grasp of the nature of moral truth. So, in defining the concept of improvement of moral "information" we must avoid notions such as those of knowledge or truth. A straightforward definition might be given in terms of increasing coherence (cf. Lynch 2009: 172): improving moral information, i.e. a set of moral beliefs, is increasing its overall coherence. ${ }^{6}$ As regards the non-moral, notably empirical part of information, however, we can make use of the concept of knowledge or truth, i.e. empirical knowledge or truth, provided that empirical truth isn't identified with superassertibility. That is to say, the process of improvement of a (finite) state of information is the process of improving the morally relevant non-moral, empirical knowledge,

\footnotetext{
5 The only problematic case seems to be a gap of warrant that appears over and over again, so that there is no state of information based on which $\mathrm{P}$ is stably warrantable. But in this case, it is more than doubtful whether $P$ is true at all.

${ }^{6}$ For the problem how to define coherence see Lynch 2009 (pp. 164-168) and his list of "coherencemaking features" (p. 167), which are: mutual explanatory support, predictive power, simplicity, completeness and consistency. A framework grows in coherence iff, on balance, it shows more of these features or some of them to a greater degree (ibid. p. 171).
} 
i.e. acquiring true empirical information relevant for one's moral judgements and abandoning false empirical beliefs, while increasing the coherence of the overall state of information. Superassertibility thus conceived comes close to Lynch's concept of concordance (Lynch 2009: 176). In fact, concordance is a special case of superassertibility, which is neutral with respect to the question as to what constitutes moral warrant or what type of epistemology should be adopted. If one takes, as is naturally suggested within an antirealist framework, coherentism to be the epistemology of choice for the moral domain, moral superassertibility as defined above is concordance.

\section{The Argument from Faultless Disagreement and the EC-Deduction}

Objectivist antirealism, however, faces a serious problem that is based on the argument from faultless disagreement_ an argument that originally has been put forward against meta-ethical realism but ultimately applies to any objectivist position. The argument is this. There are moral disagreements, e.g. the on-going disagreement between those who morally disapprove of medically assisted suicide and its proponents, which seem to be irresolvable by rational means: no matter what improvements of the state of information and what improvements of the cognitive or epistemic abilities of the parties involved in the disagreement we might imagine, the disagreement seems to be intractable. And even if these improvements might be thought of as leading to an all-encompassing state of information and to cognitive or epistemic perfection, we still are inclined to believe in the disagreement's rational irresolvability. And this pre-theoretic thought that cognitively faultless moral disagreement is possible builds the main premise of the argument from faultless disagreement, which says that the following cannot be ruled out a priori:

(CFD) There are possible cases of cognitively faultless moral disagreement

And CFD yields a contradiction, in conjunction with two further premises. One premise is the in-principle accessibility of moral truth, i.e. the thought that moral truth is not beyond our reach and does not transcend our cognitive faculty. Wright (1992, 2002) terms it the evidential or epistemic constraint on moral truth:

(EC) For any moral proposition $\mathrm{P}$ : if $\mathrm{P}$, then it is feasible to know that $\mathrm{P}$

The other premise is what I call the Error Principle:

(EP) To believe the negation of something knowable, or to believe something the negation of which is knowable, does involve a cognitive shortcoming

So, the argument from faultless disagreement can be captured by a version of Wright's Simple Deduction, viz. his EC-Deduction, in which he only tacitly employs 
the Error Principle (for deriving line (5) from line (4) within his own presentation of the deduction). The EC-Deduction essentially runs as follows ${ }^{7}$ :

\begin{tabular}{|c|c|c|}
\hline (1) & $\begin{array}{l}\text { A believes that } \mathrm{P} \text { and } \mathrm{B} \text { believes that not- } \mathrm{P} \text {, } \\
\text { and neither has any cognitive shortcoming }\end{array}$ & CFD \\
\hline (2) & If $\mathrm{P}$, then it is feasible to know that $\mathrm{P}$ & $\mathrm{EC}$ \\
\hline (3) & $\begin{array}{l}\text { To believe the negation of something feasibly knowable, } \\
\text { or to believe something the negation of which is feasibly }\end{array}$ & \\
\hline & knowable, does involve a cognitive shortcoming & $\mathrm{EP}$ \\
\hline (4) & $\mathrm{P}$ & Ass. for RAA \\
\hline (5) & B believes the negation of something feasibly knowable & $(1),(2),(4)$ \\
\hline (6) & B has a cognitive shortcoming & $(3),(5)$ \\
\hline (7) & Not-P & (1), (4), (6), RAA \\
\hline$(8)$ & A believes something the negation of which is feasibly knowable & $(1),(2),(7)$ \\
\hline (9) & A has a cognitive shortcoming & (3), (8) \\
\hline
\end{tabular}

Provided the deduction is sound, at least one of its premises, CFD, EC or EP, is false and must be rejected.

A promising strategy to rebut this argument is to reject EP (for details see Harth 2018 and Tersman 2006: 63-82): one can believe the negation of a feasibly knowable proposition without having a cognitive shortcoming. ${ }^{8}$ Suppose $\mathrm{P}$ is feasibly knowable and a thinker $\mathrm{T}$ believes the negation of P. Does $\mathrm{T}$ necessarily have a cognitive shortcoming? It doesn't seem so. The reason is that T's cognitive faultlessness alone does not guarantee that $\mathrm{T}$ believes only true propositions. Put differently, accessibility of truth does not mean that necessarily any cognitively faultless thinker has the belief or acquires the knowledge in question. Cognitive faultlessness does not imply that a cognitively faultless thinker necessarily acquires solely true beliefs. For cognitive faultlessness at most guarantees that one has (all relevant) correct starting points, e.g. moral intuitions or moral perceptions (if there are any), and is guilty of no epistemic shortcoming, i.e. doesn't make inferential mistakes. Yet epistemic faultlessness does not guarantee the truth of all the conclusions derived from the starting points, or the beliefs they immediately generate, if the epistemic process starting off with these beliefs involves non-deductive, i.e. non-truth-preserving inference, e.g. inductive

\footnotetext{
7 This is my version of the deduction in which I made explicit all its premises for a better assessment.

${ }^{8}$ What exactly is a cognitive shortcoming? For our purposes here it might suffice to say this. A cognitive shortcoming can be regarded as any defectiveness that must add to the mere holding of a false belief (which in itself is not a cognitive shortcoming) in order that one holds the false belief in the first place, so that the shortcoming is located somewhere in the pedigree of a (false) belief. For further illumination, a list of paradigmatic cases of cognitive shortcoming might helpful (see also Enoch 2009: 41; Tersman 1998: 360; Tersman 2006: 67): inferential mistakes, i.e. logical errors and illegitimate non-deductive inferences, hasty conclusions, mistakes in weighting, rating or balancing reasons and counter-arguments, lack of intellectual rigor and conceptual accurateness, lack of astuteness, insufficient intellectual power, e.g. to grasp higher complexities, lack of ingenuity and imagination, e.g. for creating and applying thought experiments, and for finding new hypotheses, conclusions, reasons, objections and counterexamples (for more details see Author's Paper II).
} 
inference or inference to the best explanation. And if one abandons such starting points at all (as epistemological coherentists do), but does solely countenance so-called considered judgements or initially credible beliefs to start the search for a reflective equilibrium or a maximum coherent system of beliefs (cf. Brun 2014; Daniels 1979; Elgin 2005; Rawls 1951, 1971), then different such judgements or beliefs might lead (especially in conjunction with non-deductive reasoning) to divergent and incompatible reflective equilibria or maximum coherent systems of beliefs. So cognitively faultless thinkers, in addition, have to make suitable considered judgements, or have to hold suitable initially credible beliefs, or they have to make suitable non-deductive inferences, in order to really acquire moral knowledge. Accordingly, Tersman (2006: 70-71) points to an important distinction as regards the notion, or notions, of epistemic inaccessibility: weak and strong inaccessibility. Since inaccessibility is the denial of accessibility, the distinction can also be couched in terms of strong and weak accessibility, respectively. Given the truth of a proposition P, strong and weak accessibility of $\mathrm{P}$ are:

$\left(\mathrm{AC}^{\mathrm{S}}\right)$ Necessarily, for any thinker $\mathrm{T}$ : if $\mathrm{T}$ is cognitively faultless, $\mathrm{T}$ knows that $\mathrm{P}$

\section{$\left(\mathrm{AC}^{\mathrm{W}}\right)$ Possibly, some cognitively faultless thinkers know that $\mathrm{P}$}

$\mathrm{EC}$ is only plausible in the weak sense of accessibility, $\left(\mathrm{AC}^{\mathrm{W}}\right)$, since whether or not a cognitively faultless thinker acquires knowledge of $\mathrm{P}$ might, in addition to her cognitive blamelessness, also depend on the suitability of her considered judgements (initially credible beliefs) and her non-deductive inferences. Whereas the Error Principle, EP, is uncontested only in the strong sense of accessibility $\left(\mathrm{AC}^{\mathrm{S}}\right)$ : it only involves a cognitive shortcoming to belief the negation of a proposition that any cognitively faultless thinker necessarily knows or to believe a proposition the negation of which any cognitively faultless thinker necessarily knows. This holds by definition of strong accessibility. And since for EC and EP two different notions of accessibility must be employed, the EC-Deduction is not sound because of equivocation. So, we seem to be in a position to block the EC-Deduction. The possibility of unsuitable initially credible beliefs and unsuitable non-deductive inferences explains why the Error Principle doesn't hold when read it in the weak sense of "knowable". So, it explains why even a cognitively faultless thinker might believe the negation of a proposition that is knowable or might believe a proposition the negation of which is knowable-knowable in the weak sense, of course: knowable for somebody with suitable considered judgements or suitable non-deductive inferences.

The upshot is, realists are able to block the EC-Deduction, and so to rebut the argument from faultless disagreement: they might accept its premises, CFD, EC and EP, but claim an equivocation as regards epistemic accessibility, by distinguishing two different such notions as employed in EC and EP: weak and strong accessibility.

Although antirealists put forward the argument from faultless disagreement against realism, the contradiction derived by the EC-Deduction does not challenge 
realism in particular; it rather challenges any meta-ethical position that ascribes objectivity to moral judgements. So, our objectivist antirealist has to block the deduction as well. And, at first glance, she seems to succeed in the same manner as the realist, viz. by accepting the premises but claiming an equivocation as regards knowability. For, although antirealist truth is defined in epistemic terms and so is epistemically constrained, the antirealist definition of moral truth, $(\mathrm{S})$, does not imply the strong reading of EC, but at most the weak EC: if $\mathrm{P}$ is true, possibly, there is some cognitively faultless thinker who knows that P. For, recall, moral truth is defined thus: a moral proposition $\mathrm{P}$ is true just in case there is some thinker $\mathrm{T}$ having a state of information $\mathrm{S}$ such that $\mathrm{P}$ is warrantable in $\mathrm{S}$ and remains so no matter what improvements are made to $\mathrm{S}$. Thus, the objectivist antirealist is not committed to accepting the strong EC. And since EP is only plausible in the strong reading-it only involves a cognitive shortcoming to belief the negation of a proposition that any cognitively faultless thinker knows or to believe a proposition the negation of which any cognitively faultless thinker knows-the objectivist antirealist seems to be able to block the EC-Deduction: by accepting the premises but drawing on an equivocation as regards knowability.

Unfortunately, however, this solution is not available to the objectivist antirealist, since for her - in contrast to the realist-CFD poses the following problem. If cognitively faultless disagreement is possible, then a disagreement is possible in which a thinker A might stably warrant $\mathrm{P}$ and another thinker $\mathrm{B}$ might stably warrant not-P. So, if CFD holds, it is possible that both $\mathrm{P}$ and not-P are superassertible. Put differently, within our objectivist, i.e. especially non-relativist antirealist framework, CFD implies that $\mathrm{P}$ and not-P might be true together-a contradiction. Thus, within the objectivist camp, the realist alone is in a position to block the EC-Deduction by drawing on an equivocation as regards knowability. The objectivist antirealist, in contrast, has to reject $C F D$ and, in addition, has to explain why this pre-theoretic thought is misguided.

\section{An Objectivist Antirealist Rejection of CFD: The Agnostic Move}

The discussion so far has shown this. An advocate of objectivist antirealism must deny the possibility of faultless moral disagreement since this possibility leads her into contradiction. And moreover, she must explain why the pre-theoretical intuition in favour of this possibility is misleading. In the rest of the paper I will argue as follows. Instead of acknowledging that—because of the impossibility of faultless disagreement—any moral disagreement is solvable and in principle a moral agreement can be found, the proponent of objectivist antirealism might make the agnostic move, as I call it: she might claim that cognitively faultless thinkers would adopt an agnostic stance with respect to moral propositions they cannot agree on. This would explain why we have the intuition that cognitively faultless disagreement is possible, but at the same time one can deny this possibility, since faultless thinkers would have no disagreement at all as regards the relevant propositions. But even this suggestive solution is not available to objectivist antirealism, again because of its epistemic conception of truth: the assumption of agnostic faultless thinkers implies a contradiction. The preliminary 
conclusion is: the adherent of objectivist antirealism must deny the possibility of faultless moral disagreement and at the same time acknowledge that any moral disagreement can in principle be resolved by the parties reaching a moral agreement. But the latter is highly implausible: it seems to arise more from optimism or wishful thinking than from any convincing argument. That is why I reject this solution. Objectivist antirealism therefore seems to have failed. Yet, I'll discuss an attempt to ward off this failure, which tries to prevent the contradictions mentioned above by means of a logical revision: the weakening of classical logic to intuitionistic logic. But this solution does not work. Therefore, at the end of the paper, I will propose a more radical logical solution, which seems to be the only remaining one for objectivist antirealism: the abandonment of classical logic in favour of a trivalent logic.

So, let's start with our conclusion from the previous section: objectivist antirealists must reject the possibility of faultless disagreement. The prospects for such a rejection, however, seem to be dim. Which resources might the objectivist antirealist have for a convincing denial of CFD? It is utterly unpromising to argue that all cognitively faultless thinkers would agree on every moral proposition. Such an assumption seems to be guided by sheer optimism and to be based on wishful thinking, rather than on any compelling argument, especially in the light of the aforementioned considerations concerning the rejection of the Error Principle: diverging initially credible beliefs and divergent non-deductive inferences might lead even cognitively faultless thinkers to mutually incompatible moral conclusions (cf. also Loeb 1998). The only option objectivist antirealists seem to have is to argue that cognitively faultless thinkers would stay agnostic about some moral proposition-in the face of their knowledge that another cognitively faultless thinker would disagree about that proposition. According to this agnostic-stance assumption, cognitively faultless disagreement is not possible, because cognitively faultless thinkers either agree on a moral proposition or stay agnostic about it, and so do not disagree about any moral proposition. This agnostic move, or an argument to that effect, is required anyway: our objectivist antirealist has to rule out the possibility that both $\mathrm{P}$ and not-P are stably warrantable, since otherwise both $\mathrm{P}$ and not-P could be true together. Wright puts the problem thus: "It may also happen that some of the resulting enlarged states of information continue to warrant acceptance of $\mathrm{P}$, and others acceptance of not-P. And once granted to be possible at all, it's difficult to see how to exclude the thought that such a situation might persist indefinitely. In that case superassertibility would be relative to a starting point, an initial basis for acceptance or rejection. [...] That would be a kind of relativity of truth." (Wright 2006: 57). That is, the antirealist would have to accept relativism about (moral) truth if she were not in a position to "exclude the thought that such a situation might persist indefinitely" (ibid.). So how might the non-relativist, i.e. objectivist antirealist, exclude the thought that both $\mathrm{P}$ and not-P might be stably warrantable or superassertible?

The answer, I think, is this. Suppose there is moral disagreement between two epistemically highly advanced thinkers, A and B, such that both have considered what appears to be all relevant non-moral information, that they have balanced a huge number of reasons speaking in favour and disfavour of $\mathrm{P}$ and not-P, that they have acknowledged all arguments put forward by the opposite party in the disagreement, and so on. And suppose that A and B improve still further and further as regards all 
relevant aspects of their state of information, their cognitive abilities, and so on-and they still disagree about P. It seems quite plausible, then, to assume that "someday", in a highly advanced state of information and a highly improved epistemic situation, they will be (to a sufficient degree) justified in believing that no further improvement of the relevant kind could change their epistemic situation concerning $\mathrm{P}$, that no matter what further improvements were made they would continue to disagree. That is, both thinkers, while also reflecting all this, were justified in assuming that their disagreement about $\mathrm{P}$ would last indefinitely and might be rationally irresolvable, in principle. So, they would be justified, and even rationally committed, to abandon their respective moral beliefs and stop disagreeing. Hence, even if it cannot be ruled out a priori that some further improvement could decide the matter and, ultimately, solve their initial disagreement, i.e. even if this is a logical or conceptual possibility, they are, in the reflective light of their knowledge about their own informational and epistemic situation and that of their opponent, sufficiently warranted in believing that their disagreement is rationally irresolvable and so justified in abandoning a belief about $\mathrm{P} .{ }^{9}$ Hence they stay agnostic about $\mathrm{P}$ after they have reached a sufficiently high state of informational enhancement and epistemic improvement. And since this situation can be conceived of as persisting indefinitely, the thought appears irresistible that even cognitively faultless thinkers would stay agnostic in that case.

So, by this agnostic move, the objectivist antirealist seems to be able to explain why CFD is a misguided intuition, or accurately: why CFD is an improper rendering of a plausible thought. This thought is that there are rationally irresolvable moral disagreements, i.e. disagreements that cannot be resolved by rational means, or disagreements in which not even cognitively faultless thinkers would finally come to a moral agreement. And, as already pointed out, this does not imply that such disagreements would persist indefinitely, as CFD has it. So, objectivist antirealism seems to be off the hook.

Yet, unfortunately, this agnostic move doesn't seem viable for the objectivist antirealist, since a denial of CFD via the agnostic move contradicts EC-and, decisively, does so even in EC's weak reading, which is entailed by her epistemic conception of truth. That is to say, if there is no cognitively faultless thinker who accepts a proposition $\mathrm{P}$, i.e. if $\mathrm{P}$ isn't knowable, then, via contraposition of $\mathrm{EC}$, it follows not-P, and if there is no such thinker who accepts not-P, it follows the negation of not-P. So, the agnostic move conjoint with weak EC implies a contradiction: not-P and its negation, not-not-P. The upshot is, since the objectivist antirealist seems to be committed to abandoning the agnostic move but also to rejecting CFD, she seems to be committed to the view that cognitively faultless thinkers agree on every moral proposition - a conclusion that I already rejected as outright implausible. ${ }^{10}$

\footnotetext{
9 This, of course, presupposes that the relevant thinkers do not believe that any moral disagreement is rationally solvable, at least in principle.

10 Tersman (2006: 76-82) discusses a yet unmentioned strategy for arguing against CFD, which he calls the semantic move. Cognitively faultless thinkers, if they do not agree, do not disagree, rather they talk past each other, since - by relying on the principle of charity — we have to interpret their moral language or idiolect such that their disagreement is merely apparent. However, it seems rather implausible that even after durable disputing some moral question this linguistic mistake remained undetected by highly advanced thinkers. So this strategy for rejecting CFD doesn't seem to available to the objectivist antirealist.
} 


\section{Logical Revision: Intuitionistic Logic}

Is this the end of our antirealist story? At first glance, a restriction to intuitionistic logic, prominently advocated by Wright $(1992,2002)$, and even motivated by the antirealist's epistemic conception of truth, seems to offer a solution. For, as Wright (2002, 2006) pointed out, it does-within the limits of intuitionistic logic-not follow from a denial of CFD that all cognitively faultless thinkers agree on every moral proposition P. Put more precisely: it doesn't follow that cognitively faultless thinkers have the same doxastic stance towards $\mathrm{P}$, since it only follows that they do not disagree, i.e. do not not-agree. And since intuitionistically Double Negation Elimination is not valid, a denial of CFD seems to be unproblematic. That is, objectivist antirealists might deny CFD without being committed to the view that there would always be agreement between cognitively faultless thinkers. ${ }^{11}$ For clarity's sake, I'll distinguish two senses of "agreement". In the narrow sense, agreement is moral agreement, i.e. both thinkers hold the same moral belief as regards a proposition P. In the wide sense, both thinkers in the agreement just take the same doxastic stance towards $\mathrm{P}$, i.e. they either morally agree or stay agnostic about P. So, a denial of CFD—intuitionistically — does not imply that cognitively blameless thinkers always agree in the wide sense. Hence, by adopting intuitionistic logic for the moral discourse, the inacceptable conclusion that all cognitively faultless thinkers would always agree (in the wide sense) - either by moral agreement or by taking an agnostic stance - can be omitted. ${ }^{12}$ But this intuitionistic move raises the following problems:

(i) The restriction to intuitionistic logic, or the rejection of the Law of Excluded Middle, is motivated by the peculiarity of the moral discourse and moral truth, and so is applicable, initially, only to the moral discourse itself, rather than to the philosophical or meta-ethical or even empirical discourse about moral beliefs, moral disagreements, doxastic stances towards moral propositions and so on. Compare: the restriction to intuitionistic logic as regards mathematics and the mathematical discourse does not necessarily imply intuitionistic logic for meta-mathematics, the logic of which usually is construed classical. Applying intuitionistic logic to meta-mathematics is in need of argument. That is to say, an extension of intuitionistic logic from the moral discourse to its meta-discourse is in need of a specific motivation as well, since the objectivist antirealist's epistemic conception of truth, which appears to be

\footnotetext{
${ }^{11}$ Note that all the logical moves made in order to derive a contradiction from the agnostic-stance assumption and EC go through within the limits of intuitionistic logic. So even the objectivist antirealist with intuitionistic inclinations has to admit that cognitively faultless thinkers never stay agnostic about any moral proposition. But they also never disagree. So, doesn't it follow that they agree on every moral proposition? What else should they do? See below, problem (ii).

${ }^{12}$ By his intuitionistic move Wright also avoids that the denial of CFD implies realism via satisfying Cognitive Command (e.g. Wright 1992: 92-94), which, in short, says that it is a priori that any disagreement does involve a cognitive shortcoming. For a denial of CFD, i.e. the negation of "It is possible that some disagreement does not involve a cognitive shortcoming" does-intuitionistically—not imply that necessarily any disagreement does involve such shortcoming, which in turn would imply realism via satisfying Cognitive Command.
} 
the main, if not the only rationale for her intuitionistic revision of logic, is restricted to the moral discourse, while the meta-ethical, philosophical or empirical discourse (about moral beliefs, their justification and so on) is not affected, at least not affected from the outset. And to the extent to which there seems to be no motivation for an intuitionistic logical restriction of the meta-ethical discourse, or the overall philosophical discourse (since there isn't any clear division of meta-ethics and the rest of philosophy), or the empirical discourse about mental states, there are no ways and means to block the transition from denying disagreement to endorsing agreementin the wide sense at least. So, after all, it seems hard to deny: if cognitively blameless thinkers do not disagree, they morally agree or stay agnostic.

(ii) Even if we concede that intuitionistic logic is appropriate for the meta-discourse of morality as well, such logical revision doesn't seem to be of much help. The problem is this. Granted, the antirealist, due to her restriction to intuitionistic logic, can-in general-block any logical transition from the double negation of some proposition $\mathrm{P}$ to $\mathrm{P}$ itself, and so the transition from a denial of disagreement to agreement in the wide sense. But in the case under consideration it is a legitimate and urgent question as to what doxastic stance cognitively faultless thinkers would take towards a moral proposition $\mathrm{P}$ when they do not disagree about $\mathrm{P}$. On the grounds of conceptual considerations about human belief and cognition there are only three doxastic stances towards a proposition $\mathrm{P}$ that can be adopted: to believe $\mathrm{P}$ or to believe not-P (or both, at the expense of inconsistency) or to stay agnostic about P. Thus two cognitively faultless thinkers can only take the following stances towards P: (a) both thinkers agree as regards $\mathrm{P}$, i.e. either they both believe $\mathrm{P}$ or they both believe not-P, (b) they both stay agnostic about $\mathrm{P}$, i.e. they neither believe P nor believe not-P, or (c) they disagree, i.e. one thinker believes $\mathrm{P}$ and the other thinker believes not-P or at least something logically incompatible with $\mathrm{P}$, or vice versa. ${ }^{13}$ So, after all, it seems to be a priori-true on purely conceptual grounds, though not true on purely logical grounds - that cognitively faultless thinkers, when they do not disagree, either morally agree or stay agnostic. The upshot is that objectivist antirealists, since they have to reject CFD, are committed either to a convergence view, i.e. the view that all cognitively faultless thinkers agree in the narrow sense on every moral proposition, or to admitting an agnostic stance on the part of cognitively faultless thinkers about some moral propositions. But the former is highly implausible (see above) and the latter contradicts the objectivist antirealist's conception of moral truth.

In conclusion, the objectivist antirealist faces a dilemma: CFD gives rise to a contradiction via the EC-Deduction, so that she has to deny CFD, since she (in contrast to the realist) is not in a position to draw on an equivocation as regards knowability. However, a denial of CFD contradicts EC since such denial is only plausible by drawing on an agnostic stance on the part of cognitively faultless thinkers (because

\footnotetext{
13 It can be ruled out that just one of them is agnostic about $\mathrm{P}$, or more generally speaking, that some cognitive faultless thinkers stay agnostic about $\mathrm{P}$ and some other such thinkers believe $\mathrm{P}$ or believe not-P, since they are cognitively faultless and so epistemically on a par. The reasons for one such thinker to be agnostic about $\mathrm{P}$ are the reasons for any other such thinker to stay agnostic as well.
} 
a convergence view is highly questionable). But the agnostic move contradicts the objectivist antirealist's conception of moral truth, even within intuitionistic limits. Is this, finally, the end of objectivist antirealism?

\section{Logical Revision: A Three-Valued Logic for the Moral Discourse}

The crucial problem with the antirealist's agnostic move is that it implies a contradiction via contraposition of even weak EC: if it is not possible that a cognitively faultless thinker believes that $\mathrm{P}$, then not-P; and if it is also not possible that such thinker believes that not-P, then not not-P. So, if the objectivist antirealist could somehow block this logical transition, and so prevent the contradiction, she could make her saving agnostic move. This would also explain the actual existence of persistent moral disagreement by the assumption that such disagreement either persistently involves some undetected epistemic shortcoming that gives rise to a false belief or that it involves an undetected rational shortcoming that yields a belief when it is rational to stay agnostic. ${ }^{14}$ But how should objectivist antirealists block the fatal logical transition from the agnostic stance on the part of cognitively faultless thinkers to the denial of EC in the first place? Recall, not even a restriction to intuitionistic logic is of help here.

Hence an alternative, in a sense more radical logical revision for the moral discourse seems to be required: a suitable three-valued logic with its truth-valuesTrue, False and Indeterminate-epistemically construed, and so precisely in line with our antirealist's epistemic account of moral truth. So, for any moral proposition P:

$\mathrm{P}$ is true iff $\mathrm{P}$ is superassertible

$\mathrm{P}$ is false iff not-P is superassertible

$\mathrm{P}$ is indeterminate iff neither $\mathrm{P}$ nor not-P is superassertible.

That neither $\mathrm{P}$ nor not-P is superassertible, i.e. neither $\mathrm{P}$ nor not-P is stably warrantable, means that any cognitively sufficiently improved thinker abstains from a moral view regarding $\mathrm{P}$ and stably stays agnostic about P. As regards this indeterminate case we can assume symmetry concerning the doxastic stances of cognitively sufficiently improved, or cognitively faultless, thinkers, since such thinkers are cognitively on a par: if some of them stably stay agnostic, then all such thinkers stay so. Thus, it is ruled out that some cognitively sufficiently improved thinkers stably

\footnotetext{
14 So, according to objectivist antirealism, any moral disagreement actually does involve a cognitive shortcoming. This, however, does not imply realism via satisfying Wright's Cognitive Command constraint (e.g. Wright 1992: 92-94; see also footnote 12). If there are indeterminate moral propositions P, it involves a mistake, or a cognitive shortcoming, to believe $\mathrm{P}$ or to believe not-P. So satisfying Cognitive Command does not imply realism, provided the relevant discourse is construed as (possibly) containing indeterminate propositions. Wright didn't take into consideration this possibility when he introduced Cognitive Command, which says that a discourse exhibits Cognitive Command if it is a priori that any disagreement does involve a cognitive shortcoming. So Cognitive Command should be revised in order to imply realism: a discourse exhibits Cognitive Command if it is a priori that any disagreement does involve an untrue belief on the part of exactly one side of the disagreement.
} 
believe a moral proposition and some others do not. So, all such thinkers take the same doxastic stance: either they all stably warrant (believe) the same concerning a moral proposition $\mathrm{P}$, i.e. they all morally agree on $\mathrm{P}$, or they all stay agnostic about P. So they always agree in their doxastic stance. This, of course, is not to say that there is always moral agreement among them, since in the agnostic-stance case such thinkers do not morally agree - they rather agree not to morally agree, for which reason they stay agnostic and assume the indeterminacy of the proposition in question.

The truth-functions remain classic as long as indeterminacy is not involved, and the truth-functions as regards indeterminacy suggest themselves:

(NEG) $\quad \mathrm{P}$ is indeterminate iff not-P is indeterminate

(CON) A conjunction is indeterminate iff either both conjuncts are indeterminate or one conjunct is indeterminate and the other conjunct is true

(DIS) A disjunction is indeterminate iff either both disjuncts are indeterminate or one disjunct is indeterminate and the other disjunct is false

(COND) The conditional is defined in the usual manner via negation and disjunction

The basic truth-value tables are ${ }^{15}$ :

\begin{tabular}{|l|l|}
\hline P & Not-P \\
\hline T & F \\
\hline F & T \\
\hline I & I \\
\hline
\end{tabular}

\begin{tabular}{|l|l|l|l|}
\hline and & $\mathrm{T}$ & $\mathrm{F}$ & $\mathrm{I}$ \\
\hline $\mathrm{T}$ & $\mathrm{T}$ & $\mathrm{F}$ & $\mathrm{I}$ \\
\hline $\mathrm{F}$ & $\mathrm{F}$ & $\mathrm{F}$ & $\mathrm{F}$ \\
\hline $\mathrm{I}$ & $\mathrm{I}$ & $\mathrm{F}$ & $\mathrm{I}$ \\
\hline
\end{tabular}

\begin{tabular}{|l|l|l|l|}
\hline or & $\mathrm{T}$ & $\mathrm{F}$ & $\mathrm{I}$ \\
\hline $\mathrm{T}$ & $\mathrm{T}$ & $\mathrm{T}$ & $\mathrm{T}$ \\
\hline $\mathrm{F}$ & $\mathrm{T}$ & $\mathrm{F}$ & $\mathrm{I}$ \\
\hline $\mathrm{I}$ & $\mathrm{T}$ & $\mathrm{I}$ & $\mathrm{I}$ \\
\hline
\end{tabular}

\begin{tabular}{|l|l|l|l|}
\hline if & $\mathrm{T}$ & $\mathrm{F}$ & $\mathrm{I}$ \\
\hline $\mathrm{T}$ & $\mathrm{T}$ & $\mathrm{F}$ & $\mathrm{I}$ \\
\hline $\mathrm{F}$ & $\mathrm{T}$ & $\mathrm{T}$ & $\mathrm{T}$ \\
\hline $\mathrm{I}$ & $\mathrm{T}$ & $\mathrm{I}$ & $\mathrm{I}$ \\
\hline
\end{tabular}

This trivalent logic does prevent, as desired, the contradiction derived from the agnostic-stance assumption via contraposition of EC, since it does not endorse the Law of Excluded Middle. If cognitively sufficiently improved thinkers would stably stay agnostic about $\mathrm{P}$, so that neither $\mathrm{P}$ nor not-P is superassertible, i.e.

$\overline{15}$ These are the tables of Kleene's well-known three-valued system K3. 
neither $\mathrm{P}$ nor not-P is true, it doesn't follow-via "P is not true"- that not-P is true. For it solely follows that not-P is true or $P$ is indeterminate. And from the agnostic-stance assumption it also doesn't follow-via "not-P is not true"- that not-not-P $(=\mathrm{P})$ is true. It solely follows that not-not-P $(=\mathrm{P})$ is true or not- $P$ is indeterminate. So the stable agnostic stance on the part of cognitively sufficiently improved (or cognitively faultless) thinkers does not imply the fatal contradiction that not-P is true and not-not-P $(=\mathrm{P})$ is true. Rather, the assumption that neither $\mathrm{P}$ nor not-P is superassertible implies, since it is logically impossible that not-P and not-not-P are true together, that $\mathrm{P}$ is indeterminate-which, of course, matches the antirealist's claim that cognitively faultless or cognitively sufficiently improved thinkers stably stay agnostic about P.

It isn't and can't be the aim of this paper to develop in the full extent a threevalued logic for moral discourse-fully developed and philosophically motivated three-valued logical systems are at hand in the literature (e.g. Haack 1978; Priest 2008; Rescher 1969). Rather, my primary aim was to point out that a suitable three-valued logic is congenial to the antirealist's epistemic conception of moral truth as superassertibility and provides the proper logical revision the objectivist antirealist was looking for in order to cope with the challenge posed by the argument from faultless disagreement and the EC-Deduction. The challenge raised by the possibility of cognitively faultless moral disagreement, CFD, was this: accepting CFD contradicts the epistemic constraint on truth, EC, and denying CFD either yields a highly implausible convergence view-cognitively blameless thinkers morally agree (in the narrow sense) on every proposition-or enforces the agnostic move, which also contradicts EC. The trivalent logic indicated here provides a solution to this dilemma: it allows the objectivist antirealist rejecting CFD by making the agnostic move without contradicting EC. Hence objectivist realism conjoint with such logical revision seems to be a highly attractive metaethical theory: it inherits the main virtue commonly ascribed to realism alone, viz. moral objectivity, but shuns realism's main vices, notably the difficulty to cope with the correlation challenge.

Of course, such a trivalent revision of logic is not without problems and drawbacks (which, in my opinion, are outweighed by the benefits of objectivist antirealism). These are, among other things:

(i) There are no tautologies in this logic. For example, "P or not-P" is indeterminate, if $\mathrm{P}$ is indeterminate, and not, as might be expected, true. So, "Lying is wrong or lying is not wrong" is not a logical truth, because at truth-value I of "Lying is wrong" the disjunction is indeterminate. Intuitively, however, "Lying is wrong or lying is not wrong" is always true regardless of whether "Lying is wrong" is true or otherwise. So, this logic is a bit counterintuitive in this point. For why should our moral discourse be free of tautologies? The same applies to apparent contradictions like "Lying is wrong and lying is not wrong": Logical falsehoods also do not exist in this logic. In defence, it may be argued that any formal logic has its peculiar contra-intuitive cases, such as classical logic as regards the conditional. Moreover, our intuitions regarding moral discourse and moral language are shaped by the tradition of classical logic, so that any revision of logic must reckon with such or other contra-intuitive cases. 
All in all—and one should also consider how counterintuitive a relativist logic is, in which the statements "Lies are wrong" and "Lies are not wrong" do not necessarily contradict each other, or how contra-intuitive even the non-cognitivist "logic" is- the absence of tautologies should not be too great an objection to this trivalent logic. After all, it is a comparatively well-established logic.

(ii) Another problem might be the so-called Frege-Geach problem, originally raised against non-cognitivism or expressivism: If moral sentences are not truthapt (and thus are not apt for logical considerations at all), how are mixed sentences or mixed arguments, i.e. those consisting of moral and non-moral components, to be treated logically or semantically? Applied to our logical revision the problem might be this: Which logic is (to be) followed in mixed propositions or arguments? However, it isn't clear to me what exactly the problem is. One might also ask, for example: Is there such a problem with an intuitionistic revision of logic in a certain domain, e.g. mathematics or ethics, while other discourses remain classical? It seems that the problem, if there is any at all, is a general one, i.e. one that concerns any logical revision. Of course, such questions must be addressed-and I must leave the problem to future research.

(iii) Is it possible to extend the trivalent logic from propositional logic to predicate logic or modal logic? Since my revision is intended exclusively for moral discourse, i.e. only for moral propositions themselves, and not for the meta-level discourse, modalities can actually remain ignored. But the question concerning a trivalent predicate logic for moral discourse remains (which I am up to now not in a position to answer).

Within the framework of this paper these and other issues cannot, of course, be dealt with satisfactorily. The paper sees itself in this respect "only" as programmatic, it tries to set the agenda for future research in the direction of a middle-ground metaethical view. It is thus intended, especially as far as the trivalent logic is concerned, also as a stimulus and suggestion for future research in the direction of such a view, which in my opinion is an attractive position, but is currently largely disregarded in the debate.

The upshot is, in the face of the epistemological problems of robust realism, objectivist antirealism, on balance, seems to be the preferable overall account. And as regards the (main) antirealist alternatives, viz. non-cognitivism, error theory, fictionalism and relativism, the situation seems to be analogous; at least, it is fair to say, objectivist antirealism in conjunction with a suitable three-valued logic for the moral discourse, arguably, is not in a worse position.

Acknowledgements Open Access funding provided by Projekt DEAL.

Open Access This article is licensed under a Creative Commons Attribution 4.0 International License, which permits use, sharing, adaptation, distribution and reproduction in any medium or format, as long as you give appropriate credit to the original author(s) and the source, provide a link to the Creative Commons licence, and indicate if changes were made. The images or other third party material in this article are included in the article's Creative Commons licence, unless indicated otherwise in a credit line to the material. If material is not included in the article's Creative Commons licence and your intended use is not permitted by statutory regulation or exceeds the permitted use, you will need to obtain permission directly from the copyright holder. To view a copy of this licence, visit http://creativecommons.org/licen ses/by/4.0/. 


\section{References}

Behrends, J. (2013). Meta-normative realism, evolution, and our reasons to survive. Pacific Philosophical Quarterly, 94, 486-502.

Braddock, M. (2016). Evolutionary debunking: Can moral realists explain the reliability of our moral judgements? Philosophical Psychology, 29, 844-857.

Brun, G. (2014). Reflective equilibrium without intuitions? Ethical Theory and Moral Practice, 17, 237-252.

Clarke-Doane, J. (2012). Morality and mathematics. Ethics, 122, 313-340.

Daniels, N. (1979). Wide Reflective Equilibrium and Theory Acceptance in Ethics. The Journal of Philosophy, 76, 256-282.

Dorsey, D. (2006). A coherence theory of truth in ethics. Philosophical Studies, 117, 493-523.

Edwards, D. (2011). Simplifying alethic pluralism. The Southern Journal of Philosophy, 49, $28-48$.

Edwards, D. (2012a). Alethic vs deflationary functionalism. International Journal of Philosophical Studies, 20, 115-124.

Edwards, D. (2012b). On alethic disjunctivism. Dialectica, 66, 200-214.

Edwards, J. (1996). Anti-realist truth and concepts of superassertibility. Synthese, 109, 103-120.

Elgin, C. (2005). Can beliefs be justified through coherence alone? In M. Steup, J. Turri, \& E. Sosa (Eds.), Contemporary debates in epistemology (pp. 156-167). Oxford: Wiley.

Enoch, D. (2009). How is moral disagreement a problem for realism? Journal of Ethics, 13, 15-50.

Enoch, D. (2011). Taking morality seriously. Oxford: Oxford University Press.

Haack, S. (1978). The philosophy of logics. Cambridge: Cambridge University Press.

Harth, M. (2018). Faultless disagreement, realism and moral objectivity. Erkenntnis. https://doi. org/10.1007/s10670-018-0066-9.

Loeb, D. (1998). Moral realism and the argument from disagreement. Philosophical Studies, 90, 281-303.

Lynch, M. (2009). Truth as one and many. Oxford: Oxford University Press.

Pedersen, N. (2010). Stabilizing alethic pluralism. The Philosophical Quarterly, 60, 92-108.

Pedersen, N. (2012a). True alethic functionalism? International Journal of Philosophical Studies, 20, $125-133$.

Pedersen, N. (2012b). Recent work on alethic pluralism. Analysis, 72, 588-607.

Pedersen, N., \& Wright, C. (Eds.). (2013). Truth and pluralism: Current debates. Oxford: Oxford University Press.

Priest, G. (2008). An introduction to non-classical logic. From if to is. Cambridge: Cambridge University Press.

Rawls, J. (1951). Outline of a decision procedure for ethics. Philosophical Review, 60, 177-197.

Rawls, J. (1971). A theory of justice. Cambridge, Mass: Harvard University Press.

Rescher, N. (1969). Many-valued logic. New York: McGraw Hill.

Sepielli, A. (2012). Review of taking morality seriously: Notre dame philosophical reviews. An Electronic Journal. 2012.02.38. http://ndpr.nd.edu/news/29022-taking-morality-seriously-a-defense-of-robus t-realism.

Skorupski, J. (1988). Critical study. Philosophical Quarterly, 38, 500-525.

Tersman, F. (1998). Crispin wright on moral disagreement. The Philosophical Quarterly, 48, 359-365.

Tersman, F. (2006). Moral disagreement. Cambridge: Cambridge University Press.

Wright, C. (1992). Truth and objectivity. Cambridge, Mass: Harvard University Press.

Wright, C. (1996). Truth in ethics. In B. Hooker (Ed.), Truth in ethics (pp. 1-18). Oxford: Oxford University Press.

Wright, C. (2002). Relativism and classical logic. In A. O'Hear (Ed.), Logic, thought and language (pp. 95-118). Cambridge: Cambridge University Press.

Wright, C. (2006). Intuitionism, realism, relativism and rhubarb. In P. Greenough \& M. Lynch (Eds.), Truth and realism (pp. 38-60). Oxford: Oxford University.

Publisher's Note Springer Nature remains neutral with regard to jurisdictional claims in published maps and institutional affiliations. 